Cite this: RSC Advances, 2013, 3, 3861

Received 20th November 2012, Accepted 18th January 2013

DOI: $10.1039 /$ c3ra22955f

\section{Proline-coated gold nanoparticles as a highly efficient nanocatalyst for the enantioselective direct aldol reaction in watert}

\author{
Noureddine Khiar, ${ }^{\text {*a }}$ Raquel Navas, ${ }^{a}$ Eleonora Elhalem, ${ }^{a}$ Victoria Valdiviaab \\ and Inmaculada Fernández ${ }^{* b}$
}

www.rsc.org/advances

Reported is an efficient approach to the synthesis of watersoluble proline-coated gold nanoparticles through a place exchange reaction between pentanethiolate stabilized gold nanoparticles and a proline-tethered amphiphilic thiol. Preliminary studies show that the nanocatalyst is highly active in an enamine type aldolisation leading to the desired product with nearly perfect diastereoselectivity and enantioselectivity using water as an innocuous solvent.

\section{Introduction}

While great advances have been achieved with metal promoted asymmetric catalysis, ${ }^{1}$ the recent advent of organocatalysis has boosted the field in such a way that "man-made enzymes" are no more a utopia, but realistic targets. ${ }^{2}$ A paradigmatic example of this qualitative jump is the advances made in the aldol reaction, one of the most powerful transformations in organic chemistry. ${ }^{3}$ Many powerful processes, mainly stoichiometric, were developed by chemists in order to tackle the challenging issues of chemo-, regio-, diastereo-, and enantioselectivity presented by the aldol condensation. While these advances have allowed the total synthesis of complex polyhydroxylated products ${ }^{4}$ and large-scale production of enantiopure active pharmaceutical ingredients (API) ${ }^{5}$ they suffer from the production of stoichiometric byproducts, and do not compete with other catalytic green transformations. In biological systems, the aldol reaction is carried out by two types of aldolases, which catalyse the reaction through an enamine (type I aldolases) or zinc enolate (type II

${ }^{a}$ Instituto de Investigaciones Quimicas, C.S.I.C-Universidad de Sevilla, c/. Américo Vespucio, 49., Isla de la Cartuja, 41092 Sevilla, Spain. E-mail: khiar@iiq.csic.es; Fax: +34 954460565;; Tel: +34 954489559

${ }^{b}$ Departamento de Química Orgánica y Farmacéutica, Facultad de Farmacia, Universidad de Sevilla, c/. Professor García González, 2, 41012 Sevilla, Spain. E-mail: inmaff@us.es; Fax: +34 954556737; Tel: +34 954555993

$\dagger$ Electronic supplementary information (ESI) available: Experimental procedures for the synthesis of compounds $\mathbf{2 - 8}$, the pentanethiolate stabilized gold nanoparticle $\mathbf{9}$, the place exchange reaction for the synthesis of nanocatalyst $\mathbf{I},{ }^{1} \mathrm{H}$, and ${ }^{13} \mathrm{C}$ spectra of all the products as well as those of gold nanoparticles $\mathbf{9}$ and $\mathbf{I}$ are given. See DOI: $10.1039 / \mathrm{c} 3 \mathrm{ra} 22955 \mathrm{f}$ aldolases) mechanism. ${ }^{6}$ Since the seminal work by List et $a .^{7}$ on the intermolecular application of the proline-catalyzed direct asymmetric aldol reaction, many other transformations have been successfully catalysed by proline. ${ }^{8}$ Unlike natural enzymatic reactions, organocatalytic reactions mimicking the class I aldolase mode of action have typically been carried in organic solvents such as DMSO, DMF, or $\mathrm{CHCl}_{3}$, which are far from being considered as green solvents. ${ }^{9}$ In the presence of bulk water aldolase-type organocatalytic reactions generally result in very poor yield and stereoselectivity. Additionally, the high organocatalyst loading required generally for driving the reaction to completion constitutes a serious purification problem when the product and the catalyst do not have good separation factors. Thus an approach that allows an aldolase-type organocatalytic reaction to occur in water and permits an easy separation of the catalyst from the reaction medium is highly desirable. Many attempts were made to conduct the reaction in aqueous media, ${ }^{10}$ including attaching hydrophobic groups to the catalyst, ${ }^{11}$ conducting the reaction in micelles, ${ }^{12}$ or the use of host-guest catalytic systems. ${ }^{13}$ The strategies for the separation, recuperation and reuse of catalysts are numerous and include tethering to organic ${ }^{14}$ and inorganic supports, ${ }^{15}$ ionic liquids, ${ }^{16}$ magnetite, ${ }^{17}$ dendrimers, ${ }^{18}$ and DNA, ${ }^{19}$ with the immobilization of proline on organic supports making up the bulk of the literature reports. While often successful in the removal of the catalyst from the products, supported catalysts often suffer from lower activities (diffusion effects) and selectivities (site heterogeneity) when compared with their unsupported analogues. The emergence of nanotechnology has brought a large number of nanomaterials which can be used as semi-heterogeneous catalyst supports combining the advantages of high reactivity and easy separation. ${ }^{20}$ Their very high specific surface area confer them with high activity, while the recent advances in nanofiltration, precipitation-flocculation, facilitate their separation from the products. Functional gold nanoparticles stabilized by alkanethiol self-assembled monolayers (SAMs) exhibit excellent size, solubility, and agglomeration behaviour which qualify them quite naturally to act as nanometric supports for catalyst immobilization, Fig. 1. 


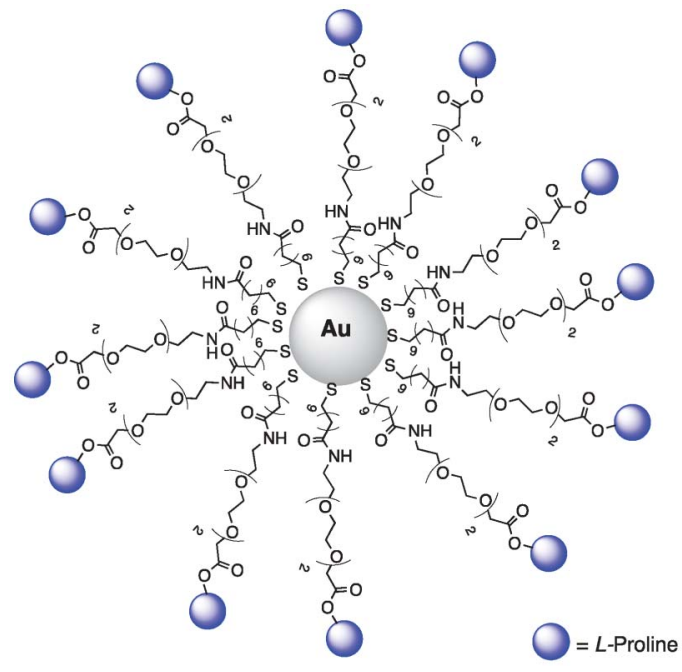

Fig. 1 Structure of proline coated nanocatalyst I.

\section{Results and discussion}

While peptides and proteins containing proline including A3 peptide, ${ }^{21}$ gelatin ${ }^{22}$ and the cell penetrating peptide $\mathrm{SAP}^{23}$ have been used for the biofunctionalization of gold nanoparticles, there are no reports on the use of proline-coated gold nanoparticles as a nanocatalyst. ${ }^{24}$ In this communication we report the design and first use of gold nanoparticles as a nanometric scaffold for the synthesis of a proline-coated water-soluble nanocatalyst I. The immobilization of proline on a support can be seen as a minimalistic version of an aldolase type I, with the proline playing the role of the enzyme's active site and the gold nanoparticle that of an oversimplified peptide backbone not directly involved in the catalytic activity. The catalyst design will be validated by using the obtained nanocatalyst I in an enamine type catalysis in bulk water, Scheme 1.

For the synthesis of our nanocatalyst with controlled density and environment of the proline on the gold surface, and to tailor the particle size, we chose to employ the place exchange reaction pioneered by Murray et $a .^{25}$ This 2 step approximation is based on the synthesis of gold nanoparticles stabilized with alkanethiolates which are exchanged in a second step by the catalyst functionalized with a reactive thiol. The gold nanoparticles stabilized by alkanethiolates are generally hydrophobic and insoluble in water, thus, our design to enhance the water solubility of the sought catalyst was the use of an amphiphilic spacer, containing both an alkyl chain to promote the exchange reaction, and a hydrophilic part derived from tetraethylene glycol to enhance the solubility of the catalyst in water. For the synthesis of the sought proline-

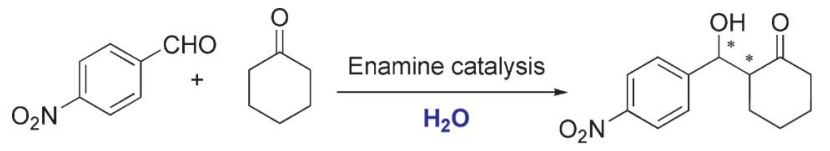

Scheme 1 Enantioselective direct aldol reaction in water.
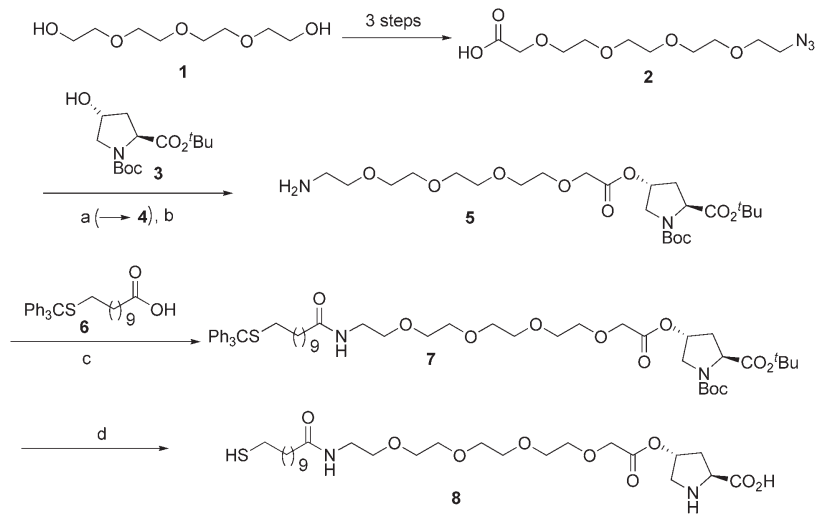

Scheme 2 Synthesis of proline-tethered amphiphilic thiol 8 . (a) $\mathrm{N}, \mathrm{N}^{\prime}$-diisopropylcarbodiimide (DIC), DMAP, $\mathrm{CH}_{2} \mathrm{Cl}_{2}, 71 \%$. (b) $\mathrm{Pd} / \mathrm{C}, \mathrm{CH}_{2} \mathrm{Cl}_{2}, 45 \%$. (c) TBTU, DIPEA, DMF, 95\%. (d) TFA, $\mathrm{Et}_{3} \mathrm{SiH}, \mathrm{CH}_{2} \mathrm{Cl}_{2}, 80 \%$.

tethered amphiphilic spacer, we used as starting material the proline derivative $\mathbf{3}$ obtained from inexpensive, commercially available trans-hydroxy proline (L-Hyp). Ester bond formation using bifunctional spacer $\mathbf{2}$ obtained in three steps from tetraethylene glycol $\mathbf{1}$ (see ESI $\dagger$ ), followed by azide reduction leads to the amine $\mathbf{5}$. Next, the reaction of the amine $\mathbf{5}$ with trityl protected mercaptoundecanoic acid 6 using $O$-(benzotriazol-1-yl)$N, N, N^{\prime}, N^{\prime}$-tetramethyluronium tetrafluoroborate (TBTU) and $N, N$-diisopropylethylamine (DIPEA) in methylene chloride as solvent afforded the amide intermediate 7 in good yield. Subsequently, trifluoroacetic acid treatment of compound 7 led to the concomitant deprotection of the Boc and trityl functions, affording the desired proline appended amphiphilic spacer $\mathbf{8}$, Scheme 2.

Gold nanoparticles stabilized with pentanethiolate groups were synthesized using the method of Brust, Schiffrin et al. by a sodium borohydride reduction of tetrachloroaureate in a biphasic system using tetraoctylammonium chloride as a phase transfer agent in the presence of pentanethiol. ${ }^{26}$ The obtained nanoparticles 9 , with a size of $2 \mathrm{~nm}$, were characterized by NMR, UV-Vis and transmission electron microscopy. TEM analysis shows that the mean particle size is about $2 \mathrm{~nm}$, which corresponds to 250 gold atoms per nanoparticle, while elemental analysis shows that there are 97 pentanethiol molecules per nanoparticle. The place exchange reaction was conducted in methylene chloride using an excess of the thiol $\mathbf{8}$ in order to assure a total coating of the nanoparticle with the catalyst. Interestingly, in the course of the reaction the desired nanoparticle precipitated in methylene chloride as a black suspension, indicating that the outer face of the nanoparticle is no longer hydrophobic. After $48 \mathrm{~h}$ and through evaporation of methylene chloride, the black solid was found to be highly soluble in water. Dialysis to remove the excess of the active thiol, followed by lyophilization of the mixture afforded the desired water-soluble proline-coated gold nanoparticle $\mathbf{I}$ in pure form, Scheme 3.

${ }^{1} \mathrm{H}$ NMR analysis shows that the place exchange reaction takes place in quantitative yield and that mostly all the pentanethiolates on the gold nanoparticle surface were exchanged with the 


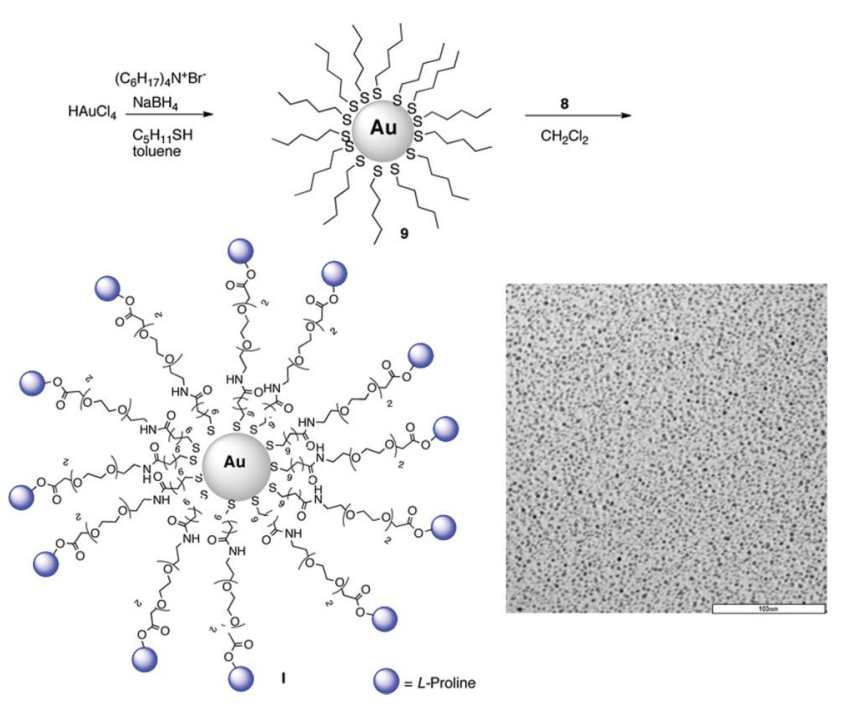

Scheme 3 Place exchange synthesis and TEM image of AuNP I.

functional thiol (see ESI $\dagger$ ). Elemental analysis indicates a ratio of 92 molecules of the catalyst per 250 gold atoms, corresponding to a molecular weight of $195 \mathrm{kD}$, and to $0.48 \mathrm{mmol}$ of ligand per gram of the nanoparticle.

Once obtained, the nanocatalyst was used in the model reaction of the direct aldol reaction between $p$-nitrobenzaldehyde $\mathbf{1 0}$ and cyclohexanone $\mathbf{1 1}$ in pure water as solvent (Scheme 4).

We were delighted to find that the nanocatalyst I is highly efficient in the direct aldol reaction as the product $\mathbf{1 2}$ was obtained in quantitative yield with nearly total diastereoselection and enantioselection in favor of the 12-anti isomer (Scheme 4). The first assays were conducted using $30 \mathrm{~mol} \%$ of the catalyst, typical in this transformation, but in view of the efficiency of the nanocatalyst, the catalyst loading could be reduced to $2.5 \mathrm{~mol} \%$ without any loss in the diastereoselectivity nor in the enantioselectivity. Interestingly, in all cases, once the reaction had finished (24 h), a simple extraction with methylene chloride led to compound 12-anti as a single isomer in pure form, as catalyst $\mathbf{I}$ remained in the aqueous phase. Preliminary attempts to recycle the catalyst were tried, and show that the catalyst is still highly enantioselective until the third run (90\% de, and 98\% ee), even though the yield dropped significantly (30\%). Taking into account the smoothness of the experimental conditions, the leaching of the catalyst ${ }^{27}$ can be ruled out, and the decrease of the chemical yield could be due to the aggregation of the nanoparticles during the extraction step.

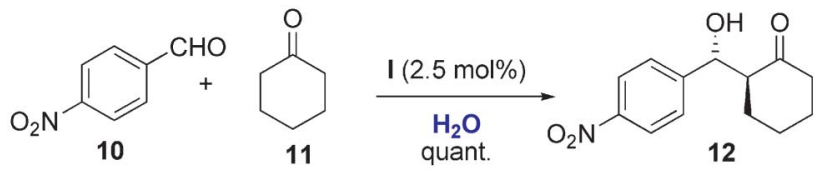

Scheme 4 Direct aldol reaction of $p$-nitrobenzaldehyde $\mathbf{1 0}$ and cyclohexanone $\mathbf{1 1}$ in water using nanocatalyst $\mathbf{I}$.

\section{Conclusions}

In conclusion, we have reported an efficient approach for the synthesis of a type I aldolase mimic nanocatalyst by a place exchange approach between a proline tethered-amphiphilic thiol and a gold nanoparticle stabilized with pentanethiolate ligands. The obtained $2 \mathrm{~nm}$ nanoparticles, containing $0.48 \mathrm{mmol} \mathrm{g}^{-1}$ of the catalyst, are highly soluble in water. The nanocatalyst is highly active in an enamine type direct aldol reaction, as only $2.5 \mathrm{~mol} \%$ is needed to afford the desired product in quantitative yield with nearly perfect diastereoselectivity and enantioselectivity using water as a green solvent. Work directed toward the determination of the scope of the catalyst in other catalytic processes, as well as to improve the experimental conditions in order to recycle the catalyst efficiently are under active investigation and will be reported in due course.

\section{Acknowledgements}

This work was supported by the Ministerio de Economia y Competitividad (grant no. CTQ2010-21755-CO2-00), and the Junta de Andalucía (P07-FQM-2774). We acknowledge CITIUS for TEM and NMR facilities.

\section{Notes and references}

1 (a) B. Trost, Proc. Natl. Acad. Sci. U. S. A., 2004, 101, 5348; (b) R. Noyori, M. Kitamura and T. Ohkuma, Proc. Natl. Acad. Sci. U. S. A., 2004, 101, 5356; (c) T. P. Yoon and E. N. Jacobsen, Science, 2003, 299, 1691.

2 (a) C. Grondal, M. Jeanty and D. Enders, Nat. Chem., 2010, 2, 167; (b) A. Dondoni and A. Massi, Angew. Chem., Int. Ed., 2008, 47, 167; (c) A. G. Doyle and E. N. Jacobsen, Chem. Rev., 2007, 107, 5596; (d) S. Mukherjee, J. W. Yang, S. Hoffmann and B. List, Chem. Rev., 2007, 107, 5471.

3 Modern Aldol Reactions, ed. R. Marwald, Wiley-VCH, Berlin, 2004.

4 O. Loiseleur, G. Koch and T. Wagner, Org. Process Res. Dev., 2004, 8, 597.

5 V. Farina, J. T. Reeves, C. H. sennayake and J. J. Song, Chem. Rev., 2006, 106, 2734.

6 T. D. Machajewsky and C. H. Wong, Angew. Chem., Int. Ed., 2000, 39, 1352.

7 B. List, R. Lerner and C. F. Barbas III, J. Am. Chem. Soc., 2000, $122,2395$.

8 (a) S. Mukherjee, J. W. Wang, S. Hoffmann and B. List, Chem. Rev., 2007, 107, 5471; (b) G. Guillena, C. Najera and D. Ramon, Tetrahedron: Asymmetry, 2007, 18, 2249.

9 (a) Y. Uozomi, Synlett, 2010, 1988; (b) P. J. Walsh, H. M. Li and C. A. De Parrodi, Chem. Rev., 2007, 107, 2503; (c) J. Mlynarski and J. Paradowska, Chem. Soc. Rev., 2008, 37, 1502.

10 (a) J. Mlynarski and J. Paradowska, Chem. Soc. Rev., 2008, 37, 1502; (b) N. Mase and C. F. Barbas III, Org. Biomol. Chem., 2010, 8, 4043.

11 (a) N. Mase, Y. Nakai, N. Ohara, H. Yoda, K. Takabe, F. Tanaka and C. F. Barbas III, J. Am. Chem. Soc., 2006, 128, 734; (b) S. Aratake, T. Itoh, T. Okano, N. Nagae, T. Sumija, M. Shoji and Y. Hayashi, Chem.-Eur. J., 2007, 13, 10246.

12 Y. Hayashi, S. Aratake, T. Okano, J. Takahashi, T. Sumija and M. Shoji, Angew. Chem., Int. Ed., 2007, 46, 5527. 
13 J. Huang, X. Zhang and D. W. Armstrong, Angew. Chem., Int. Ed., 2006, 45, 9073.

14 (a) M. Benaglia, G. Celentano and F. Cozzi, Adv. Synth. Catal., 2001, 343, 171; (b) M. Benaglia, M. Cinquini and F. Cozzi, Adv. Synth. Catal., 2002, 343, 533; (c) D. Font, C. Jimeno and M. A. Pericàs, Org. Lett., 2006, 8, 4653; (d) D. Font Sayalero, S. Bastero, A. C. Jimeno and M. A. Pericàs, Org. Lett., 2008, 10, 337; (e) F. Giacalone, M. Gruttadauria, A. Mossuto Marculescu, F. D’Anna and R. Noto, Catal. Commun., 2008, 9, 1477.

15 (a) F. Calderón, R. Fernández, F. Sánchez and A. FernándezMayoralas, Adv. Synth. Catal., 2005, 347, 1395; (b) J. Yan and L. Wang, Chirality, 2009, 21, 413.

16 (a) W. Miao and T. H. Chan, Adv. Synth. Catal., 2006, 348, 1711; (b) M. Gruttadauria, S. Riela, C. Aprile, P.L. Meo, F. D‘Anna and R. Noto, Adv. Synth. Catal., 2006, 348, 82; (c) C. Aprile, F. Giacalon, M. Gruttadauria, A. M Marculescu, R. Noto, J. D. Revell and H. Wennemers, Green Chem., 2007, 9, 1328.

17 G. Chouhan, D. Wang and H. Alper, Chem. Commun., 2007, 4809.

18 (a) Y. Wu, Y. Zhang, M. Yu, G. Zhao and S. Wang, Org. Lett., 2006, 8, 4417; (b) T. Kehat and M. Portnoy, Chem. Commun.,
2007, 2823; (c) J. Kofoed, T. Darbre and J.-L. Reymond, Org. Biomol. Chem., 2006, 4, 3268.

19 Z. Tang and A. Marx, Angew. Chem., Int. Ed., 2007, 46, 7297.

20 (a) S. Roy and M. A. Pericàs, Org. Biomol. Chem., 2009, 7, 2669; (b) A. Schätz, O. Reiser and W.J. Stark, Chem.-Eur. J., 2010, 16, 8950.

21 J. M. Slocik, M. O. Stone and R. R. Naik, Small, 2005, 1, 1048. 22 L. Lu, K. Ai and Y. Ozaki, Langmuir, 2008, 24, 1058.

23 S. Pujals, N. G. Bastffls, E. Pereiro, C. Lopez-Iglesias, V. F. Puntes, M. J. Kogan and E. Giralt, ChemBioChem, 2009, 10, 1025.

24 S. Rai, S. Kumar and H. Singh, Bull. Mater. Sci., 2009, 35, 291. 25 (a) M. J. Hostetler, S. J. Green, J. J. Stokes and R. W. Murray, J. Am. Chem. Soc., 1996, 118, 4212; (b) M. J. Hostetler, A. C. Templeton and R. W. Murray, Langmuir, 1999, 15, 3782.

26 M. Brust, M. Walker, D. Bethell, D. J Schiffrin and R. Whyman, J. Chem. Soc., Chem. Commun., 1994, 801.

27 (a) L. D. Pachón and G. Rothenberg, Appl. Organomet. Chem., 2008, 22, 288; (b) H. Cong and J. A. Porco, ACS Catal., 2011, 2, 65. 